\title{
Titration of isoflurane using BIS index improves early recovery of elderly patients undergoing orthopedic surgeries
}

\author{
[Le titrage de l'isoflurane à l'aide du BIS peut hâter la récupération des patients \\ âgés en chirurgie orthopédique]
}

Jean Wong FRCPC, Dajun Song MD, Hannah Blanshard FRCA, Deidre Grady MD, Frances Chung FRCPC

Purpose: This study was designed to investigate the effect of bispectral index (BIS) monitoring on the recovery profiles, level of postoperative cognitive dysfunction, and anesthetic drug requirements of elderly patients undergoing elective orthopedic surgery with general anesthesia.

Methods: Sixty-eight patients over the age of 60 were randomized into one of two groups. In the standard practice (SP) group, the anesthesiologists were blinded to the BIS value, and isoflurane was titrated according to standard clinical practice. In the BIS group, isoflurane was titrated to maintain a BIS value between 50-60.

Results: The total isoflurane usage was 30\% lower in the BIS group compared to the $\mathrm{SP}$ group $(5.6 \pm 3 \mathrm{vs} 7.7 \pm 3 \mathrm{~mL}, P$ $<0.05)$. The time to orientation was faster in the BIS group compared to the SP group $(9.5 \pm 3 \mathrm{vs} \mid 3.1 \pm 4 \mathrm{~min}, P<0.00$ I). There were no differences in the postoperative psychometric tests between the two groups.

Conclusions: There was no difference in the level of postoperative cognitive dysfunction between the two groups. However, titration of isoflurane using the BIS index decreased utilization of isoflurane and contributed to faster emergence of elderly patients undergoing elective knee or hip replacement surgery.

Objectif : Rechercher l'effet du monitorage par l'index bispectral (BIS) sur les profils de récupération, le niveau de déficit cognitif postopératoire et les besoins d'anesthésiques chez des patients âgés qui subissent une intervention orthopédique non urgente avec anesthésie générale.

Méthode : Soixante-huit patients de plus de 60 ans ont été répartis au hasard en deux groupes. Pour ceux du groupe de pratique courante
(PC), la valeur du BIS n'était pas connue des anesthésiologistes et l'isoflurane a été titré selon les normes de la pratique clinique. Pour les patients du groupe BIS, l'isoflurane a été titré de façon à maintenir un BIS entre 50 et 60 .

Résultats : L'utilisation totale d'isoflurane a été plus basse de $30 \%$ dans le groupe $B / S$, comparé au groupe $P C(5,6 \pm 3$ vs 7,7 $\pm 3 \mathrm{~mL}$, $P<0,05)$. Le retour à la conscience a été plus rapide dans le groupe $B / S$, comparé au groupe $P C(9,5 \pm 3$ vs $13,1 \pm 4$ min, $P<0,001)$. Les tests psychométriques postopératoires n'ont présenté aucune différence intergroupe.

Conclusion : Le niveau de déficit cognitif postopératoire n'était pas différent d'un groupe à l'autre. Cependant, le titrage de l'isoflurane à l'aide de l'index BIS a permis de réduire l'utilisation d'isoflurane et a favorisé une récupération plus rapide chez des patients âgés qui subissent la mise en place d'une prothèse totale de hanche.

H E percentage of the population over the
age of 65 will increase to approximately
$12.5 \%$ by the beginning of the $21^{\text {st }}$ centu-
ry. ${ }^{1}$ This population has a high likelihood of requiring some type of surgical intervention, thus a greater number of elderly patients will present for anesthesia and surgery. ${ }^{2}$ The incidence of postoperative cognitive deficits in general surgical patients has been reported to be $5-10 \%$ for all age groups, and increases to $10-15 \%$ in elderly patients. ${ }^{3-5}$

From the Department of Anesthesia, Toronto Western Hospital, University Health Network, University of Toronto, Toronto, Ontario, Canada.

Address correspondence to: Dr. Jean Wong, Department of Anesthesia, Toronto Western Hospital, University Health Network,

University of Toronto, 399 Bathurst Street, Toronto, Ontario M5T 2S8, Canada. Phone: 416-603-5118; Fax: 416-603-6494;

E-mail: jean_wong@yahoo.com

Supported in part by a grant from Aspect Medical, Newton, MA, USA.

Accepted for publication August 10, 2001.

Revision accepted October 22, 2001. 
Postoperative cognitive dysfunction may contribute to increased perioperative morbidity. ${ }^{6}$ Therefore, it is important to minimize the risk of postoperative cognitive dysfunction.

The bispectral index (BIS) is a continuous processed electroencephalography parameter that has been developed to measure the hypnotic effects of anesthetic and sedative agents on the brain. ${ }^{7}$ Previous studies have shown that BIS guided titration of the hypnotic agents propofol, desflurane, and sevoflurane led to faster recovery profiles. ${ }^{8,9}$ The elderly orthopedic patient population may be at higher risk for delayed recovery and postoperative cognitive dysfunction, thus this group of patients may benefit from BIS monitoring.

This study was designed to investigate whether BIS monitoring improves clinical anesthetic delivery, recovery profiles, and decreases the level of postoperative cognitive dysfunction in elderly patients undergoing total knee or hip replacement surgery with general anesthesia compared to standard clinical practice.

\section{Methods}

Approval was obtained from the institutional Ethics Committee for this prospective, randomized controlled trial. Informed consent was obtained from all patients. Inclusion criteria were ASA class I-III patients $>60 \mathrm{yr}$ of age scheduled for elective orthopedic knee or hip replacement surgery.

Exclusion criteria were significant cardiorespiratory or other end-organ disease, depression or psychiatric disorders, dementia, previous cerebrovascular accident, head trauma, inadequate command of English, and drug or alcohol abuse. Patients were excluded if they scored $<24$ on the preoperative baseline Mini Mental State Exam (MMSE) performed upon arrival in the same day admission unit.

Patients were randomized to receive general anesthesia with either BIS guided titration of anesthesia or standard clinical practice. A block randomization with concealed varying block sizes was performed with computer generated random numbers.

Preoperatively, a research assistant interviewed the patients and conducted psychometric tests including the MMSE, ${ }^{10-12}$ Trieger dot test ${ }^{13}$ and digit symbol substitution test (DSST). No premedication was given.

Routine monitoring included a 5-lead electrocardiogram, pulse oximeter, and non-invasive blood pressure cuff. All patients had BIS sensors (Aspect Medical Systems Inc., Newton, MA, USA) applied to the forehead and temple by a research assistant. The BIS values were displayed and recorded by an Aspect EEG monitor (model A-1050, Aspect Medical Systems, Newton, MA, USA). An $i v$ infusion of normal saline was established in the patient's upper extremity. The BIS value was recorded continuously prior to induction until after the patient was awake and responding to verbal commands.

In both groups, general anesthesia was induced with propofol $1-2 \mathrm{mg} \cdot \mathrm{kg}^{-1} i \mathrm{v}$, fentanyl $2-3 \mu \mathrm{g} \cdot \mathrm{kg}^{-1} \mathrm{iv}$, midazolam $1 \mathrm{mg}$ iv and endotracheal intubation was performed after administration of rocuronium 0.6 $\mathrm{mg} \cdot \mathrm{kg}^{-1}$ iv.

All of the four anesthesiologists participating in this study had greater than five years of experience providing anesthetic patient care. In the standard practice (SP) group, the anesthesiologist was blinded to the BIS value by turning the BIS monitor away from the anesthesiologist's view. The administration of isoflurane and fentanyl were adjusted according to standard clinical practice and to provide a rapid recovery.

In the BIS group, the anesthesiologist adjusted the administration of isoflurane and fentanyl to maintain a BIS index of 50-60.

In both groups, patients were ventilated and anesthesia was maintained with isoflurane and $60-70 \%$ nitrous oxide in oxygen at $3 \mathrm{~L} \cdot \mathrm{min}^{-1}$ for the first five minutes, then the gas flow was decreased to 1.5 $\mathrm{L} \cdot \mathrm{min}^{-1}$. Intermittent bolus doses of $i v$ rocuronium $\left(0.2-0.3 \mathrm{mg} \cdot \mathrm{kg}^{-1}\right)$ were administered as needed.

In the SP group, if the patient exhibited hypertension (mean arterial pressure $>25 \%$ above baseline), and tachycardia (heart rate $>90$ beats. $\mathrm{min}^{-1}$ ), the attending anesthesiologist had the options of increasing the inspired isoflurane concentration or administering fentanyl 25-50 $\mu \mathrm{g}$ iv or labetolol 5-10 $\mathrm{mg} i v$. The mode of treatment was at the discretion of the attending anesthesiologist.

In the BIS titrated group, if the patient exhibited hypertension, or tachycardia, the mode of treatment was dependent on the BIS index. If the BIS index was $>60$, anesthesia was deepened by increasing the inspired isoflurane concentration until the BIS index was between 50-60. If the BIS index was already in the targeted range, and the patient exhibited hypertension or tachycardia, fentanyl $25-50 \mu \mathrm{g}$ iv was administered. If the BIS index was $<50$, isoflurane was decreased and fentanyl 25-50 $\mu \mathrm{g} i v$ was administered for hypertension or tachycardia if the patient showed signs of inadequate analgesia (i.e., lacrimation, grimacing, movement, etc.) or labetolol 5-10 $\mathrm{mg} i v$ was administered if the patient did not show signs of inadequate analgesia.

In both groups, $15 \mathrm{~min}$ prior to the end of surgery, fentanyl $0.5-1.0 \mu \mathrm{g} \cdot \mathrm{kg}^{-1} i v$ was administered. In the SP group, ten minutes prior to the end of surgery, the inspired concentration of isoflurane was decreased 
according to usual clinical practice. In the BIS group, ten minutes prior to the end of surgery, the isoflurane concentration was adjusted to maintain a BIS of 60-70. Reversal of neuromuscular blockade was achieved with neostigmine $\left(0.05 \mathrm{mg} \cdot \mathrm{kg}^{-1}\right)$ and glycopyrrolate $\left(0.01 \mathrm{mg} \cdot \mathrm{kg}^{-1}\right)$ five minutes prior to the discontinuation of inhalational agents. In both groups the isoflurane and nitrous oxide were discontinued at the end of surgery.

The usage $(\mathrm{mL})$ of isoflurane was calculated using the formula described by Dion (usage of volatile anesthetic $(\mathrm{mL})=$ dialed concentration $\times$ total fresh gas flow $\times$ duration at that concentration $\times$ molecular weight divided by $2412 \times$ density. $^{14}$

The times to awakening (eye opening to verbal command), extubation, and time to readiness for transfer to postanesthesia care unit (PACU) was determined at one-minute intervals from discontinuation of the isoflurane.

The time to orientation to person, place and time was determined by assessing the patient at one-minute intervals in PACU. The Aldrete score was assessed at 15-min intervals by a research assistant blinded to group assignment, to determine readiness for discharge from PACU (i.e., Aldrete score >9). ${ }^{15}$ The MMSE, DSST, and Trieger dot test were conducted at 30,60, 90 and $120 \mathrm{~min}$ after arrival in PACU, and at 24, 48, and $72 \mathrm{hr}$ postoperatively. Symptoms of clinical cognitive dysfunction (i.e., reduced ability to maintain attention to external stimuli, disorganized thinking, disorientation, memory impairment, etc. $)^{16}$ reported from nurses, family members, research assistant, or patient (all blinded to group assignment) were recorded. The patients received patient controlled analgesia (PCA) morphine postoperatively. At the 72-hr interview, the patients were asked a series of questions relating to whether they had any recall of intraoperative events (Appendix). The date of discharge from hospital and reasons for delay in discharge were recorded. The patients were interviewed by telephone at 14 days after surgery to assess whether they had any recall of intraoperative events and sleep disturbances.

Parametric data were analyzed using t tests for comparison between groups. The emergence and recovery times between the two groups were analyzed by Kaplan-Meier survival analysis using the Log Rank (Mantel-Cox) statistic. Nonparametric variables including the scores in the MMSE, DSST, and Trieger dot test between the two groups were analyzed using Kruskal Wallis test or Chi square test with Yates' correction, as appropriate. A difference in drug requirements between the two groups was tested by unpaired t test. A $P$ value of $<0.05$ was considered significant.
TABLE I Demographic data

\begin{tabular}{lll}
\hline & $\begin{array}{l}\text { Standard practice } \\
(n=31)\end{array}$ & $\begin{array}{l}\text { BIS titrated } \\
(n=29)\end{array}$ \\
\hline Age (yr) & $70 \pm 6$ & $71 \pm 5$ \\
Weight $(\mathrm{kg})$ & $84 \pm 16$ & $82 \pm 15$ \\
Height (cm) & $170 \pm 7$ & $169 \pm 9$ \\
Sex (male/female) & $21 / 10$ & $19 / 10$ \\
ASA (I / II / III) & $3 / 27 / 1$ & $2 / 24 / 3$ \\
Type of surgery (knee/hip) & $10 / 21$ & $14 / 15$ \\
Duration of surgery (min) & $92 \pm 16$ & $90 \pm 16$ \\
Duration of anesthesia (min) & $121 \pm 17$ & $120 \pm 17$ \\
\hline
\end{tabular}

Values are expressed as mean \pm SD or numbers. BIS=bispectral index.

TABLE II Intraoperative drug usage

\begin{tabular}{lll}
\hline & $\begin{array}{l}\text { Standard practice } \\
(n=31)\end{array}$ & $\begin{array}{l}\text { BIS titrated } \\
(n=29)\end{array}$ \\
\hline Propofol $(\mathrm{mg})$ & $141 \pm 43$ & $146 \pm 44$ \\
Fentanyl $(\mu \mathrm{g})$ & $310 \pm 95$ & $307 \pm 64$ \\
Isoflurane $(\mathrm{mL})$ & $7.7 \pm 3.4$ & $5.6 \pm 2.6^{*}$ \\
$i v$ fluids $(\mathrm{mL})$ & $1705 \pm 544$ & $1733 \pm 592$ \\
\hline
\end{tabular}

Values are expressed as mean $\pm \mathrm{SD} ;{ }^{*} P<0.05$. BIS=bispectral index.

Data are expressed as mean values \pm SD or numbers $(n)$.

A power analysis $(=0.05, \beta=80 \%)$ was performed prior to the initiation of the study. This analysis suggested that 28 patients in each group would be adequate to detect a $20 \%$ reduction in the times from discontinuation of anesthetics to orientation [assumption of $13 \pm 3.4$ min (mean \pm standard deviation) in the SP group based on a pilot study].

Results

Sixty-eight patients were enrolled in this study; how ever, eight patients (three from the SP group, and five from the BIS group) were excluded from the analysis for protocol violations. Two patients had bipolar disorder; two patients received propofol near the end of surgery; two patients received excessive fentanyl near the end of surgery; and one patient desaturated necessitating discontinuation of nitrous oxide intraoperatively. There was no difference in demographic data between the two groups (Table I).

The average end-tidal concentration of isoflurane during surgery was lower in the BIS group than the SP group $(0.39 \pm 0.5$ vs $0.53 \pm 0.2, P<0.001)$. The total isoflurane usage was lower $(30 \%)$ in the BIS group compared to the SP group $(5.6 \pm 3$ vs $7.7 \pm 3 \mathrm{~mL}, P$ $<0.05)$. There were no differences between the two groups in any other drug usage (Table II). 
TABLE III Recovery times

\begin{tabular}{lll}
\hline & $\begin{array}{l}\text { Standard practice } \\
(n=31)\end{array}$ & $\begin{array}{l}\text { BIS titrated } \\
(n=29)\end{array}$ \\
\hline Awakening $(\min )$ & $4.9 \pm 3.4$ & $4.0 \pm 2.1$ \\
Orientation $(\mathrm{min})$ & $13.1 \pm 3.8$ & $9.5 \pm 3.1^{*}$ \\
Aldrete score of $10(\mathrm{~min})$ & $19.1 \pm 2.1$ & $16.9 \pm 2.2^{*}$ \\
PACU discharge $(\mathrm{min})$ & $123 \pm 48$ & $111 \pm 30$ \\
\hline
\end{tabular}

Values are expressed as mean $\pm \mathrm{SD} ;{ }^{*} P<0.05$. BIS=bispectral index. PACU=postanesthesia care unit.

TABLE IV Intraoperative BIS index

\begin{tabular}{lll}
\hline & $\begin{array}{l}\text { Standard practice } \\
(n=31)\end{array}$ & $\begin{array}{l}\text { BIS titrated } \\
(n=29)\end{array}$ \\
$\begin{array}{l}\text { Preanesthesia (baseline) } \\
\begin{array}{l}\text { Average during surgery } \\
\text { (from incision to completion) }\end{array}\end{array}$ & $44 \pm 9$ & $51 \pm 4$ \\
$\begin{array}{l}\text { Average during anesthesia } \\
\text { (from intubation to }\end{array}$ & $47 \pm 7$ & $53 \pm 4^{*}$ \\
$\begin{array}{l}\text { discontinuation) } \\
\text { At discontinuation of } \\
\text { anesthesia }\end{array}$ & $64 \pm 13$ & $68 \pm 13$ \\
\hline
\end{tabular}

Values are expressed as mean $\pm S \mathrm{SD}{ }^{*} P<0.05$. BIS=bispectral index.

TABLE V Mini mental state exam scores

\begin{tabular}{|c|c|c|}
\hline & $\begin{array}{l}\text { Standard practice } \\
(n=31)\end{array}$ & $\begin{array}{l}\text { BIS titrated } \\
(n=29)\end{array}$ \\
\hline Preanesthesia baseline & $29.5 \pm 1.1$ & $29.7 \pm 0.6$ \\
\hline \multicolumn{3}{|c|}{ After discontinuation of anesthesia } \\
\hline $30 \mathrm{~min}$ & $28.4 \pm 1.7$ & $28.5 \pm 1.7$ \\
\hline $60 \mathrm{~min}$ & $29.3 \pm 1.4$ & $29.4 \pm 1.0$ \\
\hline $90 \mathrm{~min}$ & $29.8 \pm 0.9$ & $29.8 \pm 0.6$ \\
\hline $120 \mathrm{~min}$ & $29.8 \pm 0.9$ & $29.8 \pm 0.5$ \\
\hline $24 \mathrm{hr}$ & $29.7 \pm 1.0$ & $29.9 \pm 0.5$ \\
\hline $48 \mathrm{hr}$ & $29.8 \pm 0.9$ & $29.9 \pm 0.3$ \\
\hline $72 \mathrm{hr}$ & $29.8 \pm 0.9$ & $28.8 \pm 5.8$ \\
\hline
\end{tabular}

Values are expressed as mean \pm SD. BIS=bispectral index.

The time to orientation was faster in the BIS group compared to the SP group $(9.5 \pm 3$ vs $13.1 \pm 4 \mathrm{~min}, P$ $<0.001)$. A survival analysis comparison of the time to orientation after discontinuation of inhalational anesthetic agents in the BIS and SP groups is shown in the Figure. The time to achieve an Aldrete score of $>9$ was faster in the BIS group than the SP group $(16.9 \pm 2.2$ vs $19.1 \pm 2.1 \mathrm{~min}, P<0.05)$. There was a trend toward faster discharge from PACU in the BIS group than the SP group, however this did not reach statistical significance (Table III).

The average BIS index was lower in the SP group than the BIS group during surgery $(44.3 \pm 8.8$ vs 51.0

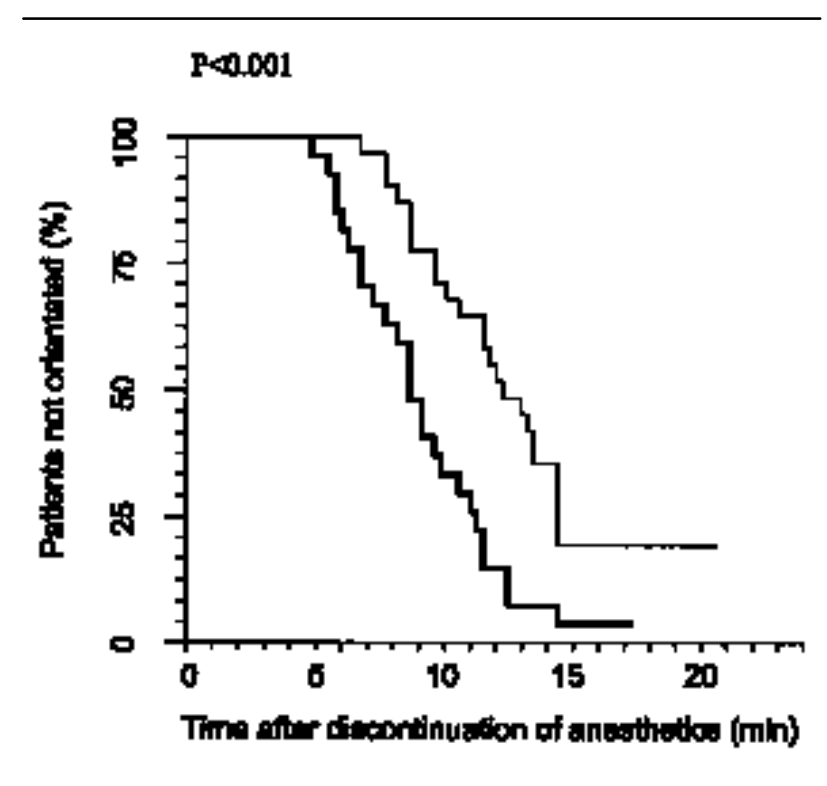

FIGURE The percentiles of the Kaplan-Meier product-limit distribution of the times from discontinuation of general anesthetics to patient orientation. Thick line: BIS-titrated group. Thin line: standard practice group.

$\pm 4.9, P<0.05)$, and during anesthesia, i.e., from induction to start of emergence $(47.2 \pm 7.1$ vs $52.5 \pm 4.4, P$ $<0.05)$. The BIS values were similar between the two groups upon discontinuation of anesthesia (Table IV). None of the patients reported awareness.

Postoperatively, there were no differences in the MMSE (Table V), Trieger Dot test, and DSST between the BIS and SP groups at any time. Clinical cognitive dysfunction was recorded in nursing notes of one patient in the SP group on postoperative days two and three.

\section{Discussion}

The use of BIS monitoring resulted in a $30 \%$ reduction in the use of inhalational anesthetic required to maintain general anesthesia in elderly patients undergoing elective hip or knee arthroplasty. The reduction in use of hypnotic agent contributed to the faster time to orientation in the BIS group than the standard practice group. The lower BIS index in the SP group compared to the BIS group during surgery and anesthesia was consistent with the higher isoflurane usage in the SP group. Our results are consistent with other studies, which have shown that BIS monitoring decreases maintenance requirements of inhalational anesthetic agents, and improves time to orientation. A randomized blinded study of female outpatients undergoing gynecologi- 
cal surgery showed that BIS monitoring reduced sevoflurane and desflurane usage by $30-38 \%$. BIS monitoring has reduced maintenance requirements of iv hypnotic anesthetic agents including etomidate $(30 \%$ reduction), ${ }^{17}$ and propofol (22\% reduction) ${ }^{8}$

In the absence of a gold standard for measuring the effects of anesthetics on the brain, autonomic activity such as changes in blood pressure and heart rate have been used to titrate anesthetic agents. However, this has been shown to have poor correlation with anesthetic depth. ${ }^{18}$ As well, the high prevalence of cardiovascular disease and subsequent drug use in elderly patients may inhibit typical hemodynamic responses to surgical stimulation.

The minimal alveolar concentration (MAC) of isoflurane and other volatile anesthetic gases decreases with increased age. ${ }^{19-21}$ Monitoring of the hypnotic effect of volatile anesthetics may help optimize the appropriate use of hypnotics, analgesics, and vasoactive drugs. A recent study examining the effect of increased age on the BIS index showed that increased age did not change the BIS index associated with clinical endpoints for sedation. As well, the BIS index was a better predictor of depth of sedation than end-tidal sevoflurane concentration. ${ }^{2}$ Another study found that increased age had no effect on the rate of BIS reduction with increasing propofol concentration. ${ }^{22}$

In our study, the faster time to orientation in the BIS vs standard practice group is consistent with other studies. In a study of ambulatory gynecological surgical patients, the times to orientation were faster in the BIS-titrated group $v s$ the control group receiving desflurane $8.4 \pm 2.4$ vs $10.5 \pm 4.2 \mathrm{~min}$, and sevoflurane $13.2 \pm 4.0$ vs $10.2 \pm 2.8$ min respectively. ${ }^{9}$ The times to reach the recovery endpoints of eye opening $(6.3 \mathrm{vs}$ $9.5 \mathrm{~min}$ ) and responding to command (6.7 vs 10.5 min) were also faster in the BIS vs standard practice group of patients receiving propofol, alfentanil and nitrous oxide. ${ }^{8}$ In our study, the time to achieve an Aldrete score $>9$ was faster in the BIS than the SP group. The trend toward faster times to discharge from PACU of patients in the BIS group may have been significant if our sample size had been larger.

A large multicentre study reported the incidence of postoperative cognitive dysfunction in elderly patients was $25.8 \%$ one week after major non-cardiac surgery, and $9.9 \%$ three months after major non-cardiac surgery. ${ }^{2}$ The authors used the MMSE, and six other neuropsychological tests. The reported incidence of postoperative cognitive dysfunction ranges between $28-41 \%$ for elderly patients in the orthopedic surgery group. ${ }^{4,5}$ The wide range for reported incidence might be attributed to differences in diagnostic criteria, pop- ulations under study, and differences in surveillance methods. ${ }^{6}$ The low incidence of reported postoperative cognitive dysfunction in our study may be related to the small sample size.

Postoperatively, we did not find significant differences in the neuropsychological tests between the BIS group and the SP group. The MMSE, Trieger Dot Test, and DSST were used in this study because they are commonly used tests of cognition which are easy to conduct, have a high compliance rate among elderly subjects, and can be used for serial testing in fluctuating conditions such as the perioperative period. ${ }^{10,13}$ The time required to complete the three tests, on average was approximately ten minutes. However, the MMSE, Trieger Dot Test, and DSST may not be sensitive enough to detect mild cognitive deficits, and possible learning effects of repeated tests may have obscured detection of postoperative deterioration in test performance. ${ }^{24}$ As well, administration of postoperative PCA morphine may have minimized any differences between the two groups.

Another limitation of this study is that the power analysis was based on detecting a difference in early recovery i.e., the time to orientation between the two groups. Thus, the sample size may be inadequate to detect a difference in the level of postoperative cognitive dysfunction between the two groups.

None of the patients in our study reported recall; however, we would require a larger sample size to find a difference between the two groups since the incidence of intraoperative recall during general anesthesia is low. ${ }^{25}$

In summary, titrating isoflurane using BIS monitoring led to a $30 \%$ reduction of isoflurane maintenance requirements, and faster emergence and earlier recovery of elderly patients undergoing elective hip or knee arthroplasty.

APPENDIX Postoperative questionnaire

What is the last thing that you remember before you went to sleep for your operation?

What is the first thing that you remember after your operation?

Can you remember anything between those two periods?

Did you dream during your operation?

\section{References}

1 Nielson WR, Gelb AW, Casey JE, Penny FJ, Merchant $R N$, Manninen PH. Long-term cognitive and social sequelae of general versus regional anesthesia during arthroplasty in the elderly. Anesthesiology 1990; 73: $1103-9$. 
2 Dodds C, Allison J. Postoperative cognitive deficit in the elderly surgical patient. Br J Anaesth 1998; 81: 449-62.

3 Gustafson Y, Brannstrom B, Berggren D, et al. A geriatric-anesthesiologic program to reduce acute confusional states in elderly patients treated for femoral neck fractures. J Am Geriatr Soc 1991; 39: 655-62.

4 Williams-Russo P, Urquhart BL, Sharrock NE, Charlson $M E$. Post-operative delirium: predictors and prognosis in elderly orthopedic patients. J Am Geriatr Soc 1992; 40: 759-67.

5 Rogers MP, Liang MH Daltroy LH, et al. Delirium after elective orthopedic surgery: risk factors and natural history. Int J Psychiatry Med 1989; 19: 109-21.

6 O'Keeffe ST, Chonchubhair AN. Postoperative delirium in the elderly. Br J Anaesth 1994, 73: 673-87.

7 Johansen JW, Sebel PS. Development and clinical application of electroencephalographic bispectrum monitoring. Anesthesiology 2000; 93: 1336-44.

8 Gan TJ, Glass PS, Windsor A, et al. Bispectral index monitoring allows faster emergence and improved recovery from propofol, alfentanil, and nitrous oxide anesthesia. Anesthesiology 1997; 87: 808-15.

9 Song D, Joshi GP, White PF. Titration of volatile anesthetics using bispectral index facilitates recovery after ambulatory anesthesia. Anesthesiology 1997; 87: 842-8.

10 Folstein MF, Folstein SE, McHugh PR. "Mini-mental state". A practical method for grading the cognitive state of patients for the clinician. J Psychiatr Res 1975; 12: 189-98.

11 Parikh SS, Chung F. Postoperative delirium in the elderly. Anesth Analg 1995; 80: 1223-32.

12 Chung FF, Chung A, Meier RH, Lautenschlaeger E, Seyone $C$. Comparison of perioperative mental function after general anaesthesia and spinal anaesthesia with intravenous sedation. Can J Anaesth 1989; 36: 382-7.

13 Letourneau JE, Denis $R$ The reliability and validity of the Trieger tests as a measure of recovery from general anesthesia in a day-care surgery unit. Anesth Prog 1983; 5: 152-5.

14 Dion $P$. The cost of anesthetic vapours (Letter). Can J Anaesth 1992; 39: 633-4.

15 Aldrete JA, Kroulik D. A postanesthetic recovery score. Anesth Analg 1970; 49: 924-34.

16 Pousada L, Leipzig RM. Rapid bedside assessment of postoperative confusion in older patients. Geriatrics 1990; 45: 59-66.

17 Doenicke AW, Roizen MF, Hoernecke R, Harbauer K, Schubert S, Zaba Z. TIVA with etomidate or propofol in day-case surgery: is the bispectral index a useful parameter to lower the maintenance dose? Anesth Analg 1999, 88: S53 (abstract).
18 Stevens WC, Dolan WM, Gibbons RT, et al. Minimum alveolar concentrations (MAC) of isoflurane with and without nitrous oxide in patients of various ages. Anesthesiology 1975; 42: 197-200.

19 Katob T, Suguro $\Upsilon$, Ikeda T, Kazama T, Ikeda K. Influence of age on awakening concentrations of sevoflurane and isoflurane. Anesth Analg 1993; 76: 348-52.

20 Gold MI, Abello D, Herrington C Minimum alveolar concentration of desflurane in patients older than 65 yr. Anesthesiology 1993; 79: 710-4.

21 Katoh T, Bito H, Sato $S$. Influence of age on hypnotic requirement, bispectral index, and 95\% spectral edge frequency associated with sedation induced by sevoflurane. Anesthesiology 2000; 92: 55-61.

22 Kazama T, Ikeda K, Morita K, et al. Comparison of the effect-site $k_{\text {eo }}$ s of propofol for blood pressure and EEG bispectral index in elderly and younger patients. Anesthesiology 1999; 90: 1517-27.

23 Moller JT, Cluitmans P, Rasmussen LS, et al. Longterm postoperative cognitive dysfunction in the elderly: ISPOCD1 study. Lancet 1998; 351: 857-61.

24 Dijkstra JB, Houx PJ, Jolles J. Cognition after major surgery in the elderly: test performance and complaints. Br J Anaesth 1999; 82: 867-74.

25 Ranta SO-V, Laurila R, Saario J, Ali-Melkkilä T, Hynynen $M$. Awareness with recall during general anesthesia: incidence and risk factors. Anesth Analg 1998; 86: 1084-9. 